\section{Benign fasciculations and Corticosteroid use: possible association? An update}

\author{
Marco Orsini, 1,2 Flavio R. Sztajnbok, ${ }^{3}$ \\ Acary Bulle Oliveira, 4 \\ Marco Antonio Araújo Leite, 1 \\ Peter Salem Júnior, \\ Marcos R.G. de Freitas, 1 \\ Osvaldo J.M. Nascimento, 1 \\ Júlio Guilherme Silva,1,2 \\ Marzia Puccioni Sholer, 5 \\ Fernando Silva Guimarães, 2 \\ Alessandra Cardoso Pereira, 3 \\ Sara Lúcia Silveira de Menezes, 2 \\ Antonio Marcos da Silva Catharino, \\ Fabrício Bino ${ }^{3}$ \\ 1Neurology Service - Antonio Pedro \\ University Hospital - Federal Fluminense \\ University - HUAP - UFF; 2Sciences \\ Rehabilitation Masters Program - \\ UNISUAM; 3 Medicine Department - \\ Grande Rio University, Rio de Janeiro; \\ 4Neurology Department - São Paulo \\ Federal University - UNIFESP, São \\ Paulo; ${ }^{5}$ Cerebrospinal Fluid Laboratory \\ and Clinical Pathology Service at the \\ Clementino Fraga Filho Hospital of the \\ Federal University of Rio de Janeiro \\ (HUCFF/UFRJ), Brazil
}

\begin{abstract}
Fasciculations are characterized by visible subtle and fast contractions of muscle, even wormlike in movement, by the contraction of a fascicle of muscle fibers. The authors present the case study of a 28-year-old patient with the appearance of migratory and diffuse fasciculations with an onset after partial tapering off of oral corticosteroides (60 mg total dose) indicated for treatment of Minimal change Glomerulopathy. Clinical Neurological physical exam allied with an ENMG, besides other complementary laboratory exams were used for screening the above-mentioned patient. Afterwards, current research relating to the topic at hand was made in order to update the data available in the Bireme, Scielo and PubMed Data Banks using the following key words: Fasciculation's, motor neuron disease, and benign fasciculations in the Portuguese, English as well as Spanish language. Although fasciculation's are most commonly associated with Motor neuron disease as well as with certain metabolic disorders, they may also be present in individuals with absolutely no underlying pathological disorders. In our case,
\end{abstract}

fasciculation potentials that have been present for six months, with no other signs of a neurogenic disorder as well as absence of laboratory findings, the patient received a diagnosis of Benign Fasciculation Syndrome (BFS).We believe that the use of corticosteroides in high doses with subsequent tapering contributed to the fasciculation's, especially due to the changes that this causes on the ionic channels. Fasciculation's are symptoms seen in a large range of conditions, and also being the main symptom of the so-called Benign Fasciculation Syndrome. We have presented an example of this clinical syndrome in a patient whose complaint was fasciculation's, with complete clinical remission of symptoms following complete tapering off of corticosteroid six months previously.

\section{Introduction}

Minimal Change Disease, formerly known as Lipoid Nephrosis, is responsible for approximately 70-90\% of childhood Nephrotic syndrome and for $10-15 \%$ of adult nephroses. 1,2 Generally speaking, it presents itself clinically as a primary renal disease, however eventually secondary to several other conditions such as: Hodgkin's disease, certain allergic states, as well as Naiads (a situation which is known as toxic interstitial nephritis. Treatment usually consists of oral therapy with corticosteroides. 2,3

Undoubtedly, fasciculation's, even isolated ones, are still considered to be one of the most ominous clinical signs for the neurologist due to their relationship with Amyotrophic Lateral Sclerosis and other motor neuron diseases. In view of this, clinical and neurophysiological reevaluation, as well as specific complementary laboratorial exams, are an integral part of these patients follow up. 4 Unfortunately, attempts at precisely outlining the true meaning of benign fasciculation's hit upon the absence of specific neurophysiological and clinical studies. Happily, fasciculation's are also present in completely normal individuals with no ther underlying pathologic processes involved. 4,5

Countless adverse side effects may arise during corticosteroid use, regardless of the dose. However, discontinuing the drug, even cautiously, is also potentially hazardous because of the possible occurrence of two events: Tapering off syndrome (Abstinence) and Secondary Adrenocortical Failure. ${ }^{6,7}$ There is no research available in the current medical literature that associate use of corticosteroids with the ocurrence of BFS. Thus, the objective of the study at hand is to present the case of a patient who began presenting with benign fasciculations at the moment of corticosteroid
Correspondence: Marco Orsini, Herotides de Oliveira, 2(801), Jardim Icaraí, Niterói, RJ, Brazil. Tel: +55.24230230 .

E-mail: orsinimarco@hotmail.com

Key words: eletroneuromyography, fasciculation's, benign fasciculation syndrome.

Received for publication: 26 May 2011. Accepted for publication: 30 August 2011.

This work is licensed under a Creative Commons Attribution NonCommercial 3.0 License (CC BYNC 3.0).

(C) Copyright M. Orsini et al., 2011

Licensee PAGEPress, Italy

Neurology International 2011; 3:e11

doi:10.4081/ni.2011.e11

tapering, in this specific case, methypredsilone.

\section{Case Report}

A 28-year-old man, medical student, reports the onset in december of 2008, after initiating tapering schedule for corticosteroids (methylprednisolone, $1 \mathrm{mg} / \mathrm{kg} /$ day), for treatment of MCGN started to present with fasciculations, diffuse in nature, migratory and intermittently. He says that the onset of symptoms coincided with the tapering of corticosteroids, which was initially at a dose of $60 \mathrm{mg} / \mathrm{kg} /$ day during 15 days, being gradually reduced to $20 \mathrm{mg} /$ day on an alternate-day schedule, unitl its complete withdrawal in 8 weeks. He also says he had previously experienced the same clinical picture when his fasciculatory symptoms lasted for 3 months following abstinence. Initially, the fasciculation's were noticed in the proximal third of his arm and the distal third of his thigh. Later on, intrinsic muscles of the hand and face as well as the shoulder girdle were also involved. They would last several days em specific regions, and, subsequently, would spread to other more distant parts of the body. Physical exertional activity would worsen the fasciculations and would sometimes evolve into painful joint/arthritic-like symptoms.

The patient denied any type of paresis, muscular atrophy or cramps. The patient was them submitted to a neurologic exam in December of 2008 , which revealed upon inspection, rapid, diffuse and visible contractions in face, trunk, upper and lower limbs. Superficial and deep reflexes were normal. No motor neuron involvement was found. Sensibility was also normal. A CBC, electrolyte profile (Potassium= $4.2 \mathrm{mEq} / \mathrm{L}), \quad($ Calcium $=5.1 \mathrm{mEq} / \mathrm{L}$, Magnesium= $2.2 \mathrm{mEq} / \mathrm{L}$, Phosphorus= 2.9 $\mathrm{mE} q / \mathrm{L})$ thyroid function, viral serology, and 
basal cortisol levels were ordered. Serum creatinine (0.8 mgldL) and Creatine Kinase (102 UL). The patient also denied neither preceding viral event, nor a bacterial one in the preceding days or weeks. All these tests proved to be normal. No chemical poisoning signs were evident upon examination. He denied being a toxic drug user. He also denied using stimulant drugs. No evidence of functional disease was found. He denied drinking or smoking. He admitted to daily ingestion of coffee, but he denied using dietary supplements. An ENMG at same month, revealed an interval between resting motor action potentials of $0.9 \mathrm{~s}$. High amplitude and duration action potentials, positive sharp waves, and fibrillation potentials were also found upon testing. No medication was prescribed. In May of 2009, after six months of its onset, the patient returned to the outpatient unit to inform the cessation and resolution of all symptoms. He was hence diagnosed with BFS and referred for follow -up.

\section{Discussion}

Fasciculations are the result of spontaneous discharges of motor units, although the exact physiological mechanism involved is not yet known. Fasciculation potentials may eventaully persist after distal nerve block, thus suggesting axonal or even anterior horn cell damage. Experimental studies support the Idea that the distal origino fasciculations may be reflected in their presence among distal axonal ramifications (arborizations). ${ }^{3-5}$ This probably represents changes in conduction properties of ionic channels, such as fluctuations in ionic gradients along axonal membranes. The distinction between benign (no association with serious neurologic conditions) and malignant fasciculations (commonly associated with degenerative neurologic conditions) should be liberally used since the most important factor here is without a doubtless is the evaluation of the morphology, duration, and number of phases of the motor action potential as well as the presence or absence of other types of spontaneous activity (acute positive waves, fibrillation potentials). It should also be noted that there are countless clinical situations in which fasciculations is a major chief complaint. ${ }^{5}$ Among several causes of fasciculations, we may include, fasciculation's in normal individuals, as a result of neurologic disorders, associated with metabolic diseases, medicationinduced and fasciculation's of systemic diseases (Table 1).5,8-16

The use of corticosteroides may lead to various manifestations such as tolerance for carbohydrates, capillary and vascular fragility, proximal myopathy, motor weakness, hypertension, osteoporosis, a greater susceptibility to infections and psychiatric symptoms among others6. It should be noted that the side effects of the same dose of corticosteroides are variable and hence heterogeneous among individuals of the same population with pharmokinetics and different plasmatic protein concentrations being the principal reasons for this. ${ }^{7}$ Nevertheless, it should also be mentioned that to the best of our knowledge now here in the current literature has it been registered that there actually exists a relationship between (BFS) and corticosteroid use, such as in our study. A hypothetical cause and effect relationship raised by our study group would be that effects of corticosteroids upon the hydroeletrolitic balance, through changes in the calcium, sodium, magnesium and potassium channels ${ }^{6,7}$ However, our patient presented with normal values. Basal cortisol levels were also normal.

Attention should also be called to the fact that the earliest complaints of our patient began during the final phase of corticosteroid tapering, with a dose of $20 \mathrm{mg} /$ day on an alternate-day schedule. Total tapering of time was eight weeks lasted eight, with the first two weeks consisting of a $60 \mathrm{mg} /$ day dose. In this case, withdrawal syndrome symptoms should also be taken into consideration. These symptoms include: anorexia, arthralgias, general weakness, weight loss, and skin exfoliation coupled with fever. ${ }^{6}$ Unfortunately, the exact mechanisms through which the withdrawal syndrome occurs are still unknown. However two main theories still are widely accepted: the changes in plasmatic concentration of corticosteroides brought on by going from a higher to a much lower dose of this drug, which will in turn induce a clinical syndrome very similar to Adrenal Failure; and elative glucocorticoide resistance leading to a hypercortisolemic state. 6,7 It should also be remembered that our patient, besides complaining of fasciculations, also complained of generalized arthralgias. Another question raised was the presence of the syndromes not associated in any way with corticosteroid use, such as neurological diseases, medical drugs, intoxications/poisonings, metabolic and systemic diseases.

In the case of ALS, a progressive and chronic degenerative neurologic disease which involves both upper and lower motor neuron neurons, seldom present fasciculation at onset. Generally speaking, fasciculation's in this case are associated clinically with other signs and symptoms such as paraparesis among other anterior horn cell lesion symptoms. Such fasciculation's in this case might be considered as vain, unsuccessful attempts at reinnervation on by surviving and still functioning motor neurons located in partially denervated muscle fibers. Although the neurologic exam of our patient was entirely normal, ENMG revealed signs of fasciculation potentials, positive waves as well as fibrillations in the various muscle groups tested. - $^{-10}$

Singh et al., ${ }^{4}$ in a study of 4 patients who were initially diagnosed with Benign Cramping and fasciculation Syndrome (SCFB), identified these same patients as progressing

Table 1. Fasciculations causes.

1 Benign fasciculations (healthy subjects)

1.1 Occasional (Mainly in Forearms, Calves and Thumb).

1.2 Caused by Coffee, Stress, Anxiety, Cigarettes.

1.3 Strenuous and high intensity exercises .

1.4 Benign fasciculations (Isolated and Persistent) - duration for months and I or years.

2 Neurogenic disorders resulting from fasciculations

2.1 Amyotrophic Lateral Sclerosis.

2.2 Spinal Muscular atrophies.

2.3 Benign monomelic amyotrophy (Hirayama disease).

2.4Kennedy Disease

2.5 Multifocal Motor Neuropathy

2.6 Acute Anterior Poliomyelitis

2.7 Radiculopathy

2.8 Peripheral Neuropathies

2.9 Plexopathy

2.10 Syringomyelia

2.11Creutzfeldt-Jakob Disease

2.12 Spinal amyotrophy of upper limbs (distal)

3 Fasciculations for metabolic diseases

3.1 Thyrotoxicosis

3.2 Tetanus

4 Fasciculations caused by drug use

4.1 Anticholinergic Drugs

$4.2 * *$ Use of Steroids (corticoids)

4.3 Organophosphates and other insecticides I pesticides (commonly in the acute intoxication).

4.4 Lithium

5 Fasciculations caused by systemic diseases

5.1 Infections, mainly viral. (HIV-1, 2, HTLV-1, syphilis)

5.2 Neurosarcoidosis 
to Amyotrophic Lateral Sclerosis. In view of this, the authors warn that a diagnosis of SCFB should not be considered accurate without a 4 to 5 year follow up following onset of clinical symptoms. According to the above-mentioned considerations, a follow up of five years duration was thus requested for the proper characterization of BFS in our specific case.

Mills KR9 proposed distinctions between fasciculation's and cramps presented in ALS and those presented in patients with BFS. This kind of distinction was sought through the firing of motor unit fibers as well as other neurophysiological parameters and standards. Fasciculation potentials were recorded in 63 muscles of 28 patients with ALS and then compared to 21 muscles in patients with BFS. It should be noted that in each muscle, in a single site/motor unit/location up to 15 fasciculation potentials were identified. Thus, the characteristics of 430 fasciculation potentials in patients diagnosed with ALS were compared to the 191 benign fasciculation's and then analyzed. Measured were the fasciculation potential itself, the area, duration and interval of firing, variation indexes of wave morphology, axonal conduction block testing, the variability of axonal conduction and the potential for producing double fasciculation potentials. The authors concluded that the potentials found in ALS were both shorter and of a much higher frequency than those with BFS. However, although firing patterns in both cases were irregular, the firing rate in the case of ALS was shown to be significantly higher. Whenever muscular weakness and neurogenic alteration were to be found on ENMG in the ALS group of patients, the firing rates in this case were much higher, however the variability indexes of wave form (morphology), the potential itself as well as the amplitude of potential area were all significantly reduced in ALS. The author concluded that wave form and fasciculation potential morphology were not good markers for distinguishing between benign as opposed to malignant fasciculation potentials. Highly complex fasciculation potentials could be identified in both instances.

Souayah et al..$^{13}$ published a case study of neurosarcoidosis which presented itself as Lower Motor neuron disease. The case was about a 43-year old male who developed progressive muscular weakness along with fasciculation in all his extremities of 4 months duration. Neurologic exam was consistent with an anterior horn cell syndrome. CSF analysis showed lymphocytic pleocytosis as well as an elevated opening pressure. The diagnosis of sarcoidosis was later confirmed through lacrimal gland biopsy. The patient was treated with a combination of intravenous immunoglobulin and corticosteroids with almost complete resolution of symptoms following discharge. We have hypothesized that the granu- lomatous inflammatory process must have compressed the ventral (motor) root of the spinal cord, hence resulting in the motor symptoms. In our case, the diagnosis of neurosarcoidosis was excluded.

Fermont J et al.,14 estimated the prevalence as well the distribution rate of fasciculation's among healthy adults, evaluating the effects of age, caffeine and physical exercise. The fasciculation's were studied using ultrasound in $\mathbf{5 8}$ healthy adults and distributed among distinct categories according to age. Questionnaires were used to determine the effects of caffeine as well as exercise on the genesis of fasciculation's. Finally, researchers tested the effects of intense of physical exercise on 10 healthy adults. Of the total of individuals studied, 25 (43\%) presented with fasciculation's on ultrasound, most of them located in the long abductor of the halux muscle. Fasciculation's were also identified to a lesser degree and intensity in the middle and proximal third of the lower limbs. The great majority of individuals who presented with fasciculation's were older than those who had never complained of having fasciculation's. It was also found that caffeine and physical activity did not play a role as far as the prevalence of fasciculation's was concerned. However, excessive, extenuating physical exercise did, in fact, cause a temporary increase in fasciculation's in the lower limbs. Our patient admitted to the use of caffeine on a daily basis as well as to practicing regular aerobic exercise, three times a week for about 50 minutes.

Such data were considered for the present case at hand, since the majority of patients in this age range made use of caffeine regularly as well as practice physical exercise, although this pattern and distribution of fasciculation's such as those found in our patient is not commonly seen under these conditions, which can provoke, in rare instances, fasciculation potentials, mainly in the eyelids, thumb and halux..$^{5,6}$

We must keep in mind that daily exercise possibly causes BFS through the release of a higher than normal amount of free radicals during prolonged exercise. Free radicals are a sub product of the cell's energy production; hence, the longer the activity and the more intense the exercise, the more free radicals are released. For this reason, athletes are subject to an overload of free radicals as well as oxidative stress. If prolonged exercise is actually related to benign fasciculation's then certainly the mechanism must involve free radicals that accumulate within nerve endings and cause prolonged muscle excitability. ${ }^{15-16}$

Singh G and Khurana G17 pointed out the effects of acute organophosphate poisoning, one of the most common kinds of poisonings seen in clinical emergency medicine. Among the principal effects are those found among the Peripheral Nervous System, which in turn results from the inactivation of the acetyl cholinesterase enzyme located among the nicotinic as well as muscarinic receptors, not only in the peripheral but also in the central nervous System as well. The main neurologic manifestations that usually occur late in the course of severe disease are fasciculation's associated with neuromuscular paralysis. Initially, however, only fasciculation's may be present. Our patient did not present with an occupational history of such poisoning neither did he show any clinical manifestations of acute clinical poisoning.

We also considered the possibility of our patient having made use of other medical drug that could induce BFS, such as Lithium, for example. Acute lithium neurotoxicity, according to Azevedo et al.18, manifests itselfs through dysarthria, ataxia and coarse tremors. Associated with acute mental confusion, there may also be frequent muscular fasciculations (myofasciculations) as well as myoclonus, with blepharospasm and aparaxia of eyelid opening also having been described. These symptoms may even evovle into convulsive seizures, coma and even death. Our patient did not use any other medication besides corticosteroids.

Our theory, therefore, is that he myofasciculations presented by our patient may have been related to corticosteroid use, not only through their systemic effects, but also through their varied effects upon polrization of ionic channels. Thus, corticosteroids, so widely used by physicians in general as well as in diverse specialties, have the potential for substantial morbi-mortality within not adequately manipulated. In view of this, corticosteroids should always be used for the least period of time necessary as to avoid unwanted side effects6.

The treatment of benign myofasciculation is always symptomatic, based especially upon antiepileptic drugs, including carbamazepine, gabapentine, and phenytoine, mostly with only partial clinical control of symptoms. The interpretation of the effect of these drugs concerning their precise mechanism of action is still speculative, although believed to be through the decrease of distal peripheral nerve ending excitability. 5

\section{Conclusions}

Fasciculations require a meticulous clinical and neurologic evaluation in order to look for the cause behind them. The diagnosis frequently is difficult to reach due to the ample range and scope of potential clinical conditions likely to cause them. We have presented a case study of a patient whose chief complaint was fasciculations, both diffuse and migratory, with subsequent remission of symptoms with- 
in six months of tapering off of oral corticosteroids, which is our most likely hypothesis. Additional studies will be necessary in the future.

\section{References}

1. Gargah TT, Lakhoua MR. Mycophenolate mofetil in treatment of childhood steroidresistant nephrotic syndrome. J Nephrol 2011;24:203-7.

2. Kari JA, El-Morshedy SM, El-Desoky S, et al. Rituximab for refractory cases of childhood nephrotic syndrome. Pediatr Nephrol 2011;26:733-7.

3. Singh V, Gibson J, McLean B, et al. Fasciculations and cramps: how benign? Report of four cases progressing to ALS. J Neurol 2010;258:573-8.

4. Mills KR. Characteristics of fasciculations in amyotrophic lateral sclerosis and the benign fasciculation syndrome. Brain 2010;133:3458-69.

5. Buainain RP, Moura LS, Oliveira ASB. Fasciculação. Rev Neurociências 2000;8: 31-4.
6. Faiçal S, Uehara MH. Efeitos sistêmicos e síndrome de retirada em tomadores crônicos de corticosteróides. Rev Ass Med Brasil 1998;44:69-74.

7. Pereira ALC, Bolzani FCB, Stefani M, Charlin R. Uso sistêmico de corticosteróides: revisão da literatura. Med Cutan Iber Lat Am 2007;35:35-50.

8. de Carvalho M, Swash M. Fasciculationcramp syndrome preceding anterior horn cell disease: an intermediate syndrome? J Neurol Neurosurg Psychiatry 2011;82:45961.

9. Mills KR. Detecting fasciculations in amyotrophic lateral sclerosis: duration of observation required. J Neurol Neurosurg Psychiatry 2011;82:549-51.

10. Chieia MA, Oliveira ASB, Silva HCA, Gabbai AA. Amyotrophic lateral sclerosis: considerations on diagnostic criteria. Arq Neuropsiquiatr 2010;68:837-42.

11. Orsini M, De Freitas MRG, Nascimento OJM, et al. Atrofia Muscular Distal Bilateral dos Membros Superiores (Síndrome de OSullivan-McLeod). Rev Bras Neurol 2010;46:43-35.

12. Neves MA0, MP, Santos VV, Nascimento OJM et al. Post-poliomyelitis syndrome: case report. Arq Neuropsiquiatr 2007; 65:528-31.

13. Souayah N, Hassan AE, Krivitskaya N, et al. Neurosarcoidosis presenting as an anterior horn syndrome. J Neuroimmunol 2010;225:132-6.

14. Fermont J, Arts IM, Overeem S, et al. Prevalence and distribution of fasciculations in healthy adults: Effect of age, caffeine consumption and exercise. Amyotroph Lateral Scler 2010;11:181-6.

15. Blexrud MD, Windebank AJ, Daube JR Long-term follow-up of 121 patients with benign fasciculations. Ann Neurol 1993; 34:622-5.

16. Kennedy G, Spence VA, Mc Laren M, et al. Oxidative stress levels are raised in chronic fatigue syndrome and are associated with clinical symptoms. Free Radical Biol Med 2005:39:584-9.

17. Singh G, Khurana D. Neurology of acute organophosphate poisoning. Neurol India 2009;57:119-25.

18. Azevedo Y, Marques CA, Lacoponi E. Ataxia prolongada associada à intoxicação por lítio. Casos Clin Psiquiatria 2000;2:18-20. 